\title{
Orexin receptors: a journey through their discovery to the development of suvorexant, the new sleeping pill
}

\author{
Anandabaskar Nishanthi*, Mourouguessine Vimal, \\ Selvarajan Sandhiya, Steven Aibor Dkhar
}

\begin{abstract}
JIPMER, Sri Manakula Vinayagar Medical College and Hospital, Puducherry, India
\end{abstract}

Received: 29 March 2016

Accepted: 27 April 2016

\section{*Correspondence to:}

Dr. Anandabaskar Nishanthi, Email: nishanthi11189 @ gmail.com

Copyright: (C) the author(s), publisher and licensee Medip Academy. This is an openaccess article distributed under the terms of the Creative Commons Attribution NonCommercial License, which permits unrestricted noncommercial use, distribution, and reproduction in any medium, provided the original work is properly cited.

\begin{abstract}
Orexin $(\mathrm{OX})$ neuropeptides acting through G-protein coupled $\mathrm{OX}_{1}$ and $\mathrm{OX}_{2}$ receptors are implicated in a variety of physiological roles including regulation of feeding, sleep-wake cycle, energy metabolism and reward pathways. Accumulating experimental evidence indicates that orexins are wake promoting neuropeptides and deficits in orexinergic neurotransmission leads to narcolepsy, a debilitating sleep disorder. This has led to a search for orexin receptor agonists for pharmacotherapy of narcolepsy. However, development of orexin receptor agonists are still in their infancy stage and it invokes further research to know whether it could turn into a reality. In addition, the role of orexin neuropeptides in promoting arousal and wakefulness has generated considerable interest in developing orexin receptor antagonists for treatment of insomnia. This quest was accomplished with the approval of suvorexant by United States food and drug administration in 2014. This remarkable discovery has opened a novel approach for treatment of insomnia through neuromodulation of orexin signaling. Hence this review focuses on the orexinergic system, their physiological action and potential role as pharmacological targets.
\end{abstract}

Keywords: OX receptors, Hypocretin receptors, Insomnia, Suvorexant, Neuropeptide

\section{INTRODUCTION}

Two independent groups of researchers discovered the orexin/hypocretin neuropeptides in 1998. De Lecea et al working on wistar rats identified a hypothalamus specific mRNA coding for a precursor protein preprohypocretin that on cleavage yielded two closely related proteins called hypocretin-1 and hypocretin-2. ${ }^{1}$ Hypocretins were named so since they were selectively located in the neurons of hypothalamus and because of their similarity to the gut peptide "secretin". Another team of researchers headed by Sakurai et al used reverse pharmacology approach for deorphanization of several orphan G-protein coupled receptors. ${ }^{2}$ These screening experiments led to the discovery of orexin neuropeptides, orexin-A and
orexin-B. These peptide ligands were named after the greek word "orexis" meaning "appetite" since they were implicated in regulation of feeding behavior. Later it was discovered that both orexins and hypocretins were similar neuropeptides and this finding ignited a debate on their naming system. In order to bring an end to this nomenclature debate and reach a consensus, the international union of basic and clinical pharmacology gave the following recommendations. ${ }^{3}$ They proposed to designate "hypocretin" for the gene and mRNA coding for the neuropeptides. The precursor protein and processed peptides were named "prepro-orexin" and "orexins A and B" respectively. Similarly, the G-protein coupled receptors for these peptides were called as "orexin receptors" and the genes that encode these 
receptors were designated as "hypocretin receptor genes". Although this nomenclature is confusing at first look especially to a novice in this field, it gives credit to the work of both the groups of scientists who discovered them.

Orexins are neuropeptides selectively produced by a group of neurons located in the dorsolateral part of the hypothalamus. They are of two types namely orexin A and B, containing 33 and 28 amino acid peptides respectively with $64 \%$ similarity to their amino acid sequences. They act on G-protein coupled receptors $\mathrm{OX}_{1}$ and $\mathrm{OX}_{2}$ orexin receptors comprised of 425 and 444 amino acids respectively. The $\mathrm{OX}_{2}$ receptors exhibit equal affinity for both orexin $\mathrm{A}$ and $\mathrm{B}$, on the other hand $\mathrm{OX}_{1}$ receptors display tenfold higher affinity for orexin-A than orexin-B. ${ }^{2}$

Immunological and molecular biological methods were used to identify the distribution of orexinergic neurons and orexin receptors. The cell bodies of orexinergic neurons are present mainly in the dorsolateral hypothalamus, whereas their nerve fibres project widely in the central nervous system especially to the thalamus, hypothalamus, brain stem and spinal cord. There are about 50,000 to 80,000 orexinergic cells in the human brain. ${ }^{4}$ The orexinergic neurons express norepinephrine, serotonin, muscarinic acetylcholine, glutamate, GABA (gamma aminobutyric acid), neuropeptide $\mathrm{Y}$, ghrelin, leptin and cholecystokinin receptors. Thus, the orexin neurons receive information about arousal and wakefulness through glutamate, GABA, acetylcholine, norepinephrine and serotonin signaling; and feeding and metabolic state through neuropeptide $\mathrm{Y}$, ghrelin, leptin and cholecystokinin signaling. ${ }^{5}$

In the central nervous system, orexinergic neurons project to the monoaminergic neurons promoting wakefulness like locus ceruleus (noradrenergic), dorsal raphe nucleus (serotonergic) and tuberomamillary nucleus (histaminergic). These nuclei are richly endowed with the orexin receptors. Locus ceruleus neurons express mainly $\mathrm{OX}_{1}$ orexin receptors, tuberomammillary nuclei expresses $\mathrm{OX}_{2}$ orexin receptors and dorsal raphe nucleus expresses both $\mathrm{OX}_{1}$ and $\mathrm{OX}_{2}$ orexin receptors. Also cholinergic neurons of pedunculopontine tegmental nucleus/laterodorsal tegmental nucleus promote wakefulness and are richly furnished with $\mathrm{OX}_{1}$ orexin receptors. ${ }^{5}$

\section{Orexin signaling mechanisms}

The orexin receptor signaling mechanisms are highly complex. In a study by Karteris et al, it was found that the orexin receptors non-specifically couple to either of the four types of G-proteins, namely Gs, Gq, Go and $\mathrm{Gi}^{6}{ }^{6} \mathrm{~A}$ similar finding was observed in another study done in Chinese hamster ovary cell lines, where the $\mathrm{OX}_{1}$ orexin receptors were reported to couple with Gs (stimulation of cAMP production), Gq (activation of phospholipase C) and Gi/o (inhibition of cAMP production). ${ }^{7}$ Studies on cultured rat cortical neurons, show that orexin ligands acting on $\mathrm{OX}_{2}$ receptors couple to Gi regulatory protein and inhibit cyclic AMP synthesis. ${ }^{8}$ A recent study on Chinese hamster ovarian cell lines has revealed other signaling mechanisms like activation of phospholipase D and release of arachidonic acid upon activation of $\mathrm{OX}_{1}$ orexin receptors. ${ }^{9}$

Orexins being excitatory neuropeptides, stimulation of their receptors lead to depolarization by the following mechanisms; (i) activation of NSCC (non - selective cation channels), (ii) stimulation of NCX (sodium calcium exchanger) and (iii) inhibition of potassium channels which are active at rest. ${ }^{10}$ Although their signaling mechanisms have been elucidated, their physiological significance still remains elusive. Further studies are needed to clarify the signaling mechanisms, second messengers involved in orexin pathway and their physiological roles. This would give us the opportunity to understand the signaling mechanisms and provide a fruitful resource for drug discovery.

\section{Physiological role of orexinergic system}

Orexin neuronal activation promotes arousal and wakefulness by modulating the monoaminergic (locus ceruleus, dorsal raphae nucleus and tuberomammillary nucleus) and cholinergic neurons (pedunculopontine tegmental nucleus/ laterodorsal tegmental nucleus) of the central nervous system. A study by Lee et al in rats demonstrated that while awake and when postural muscle tone was high, the orexin neurons discharge actively. ${ }^{11}$ Conversely, during sleep these neurons stopped firing signals. Hence, the authors concluded that orexinergic neurons stimulate wakefulness and increase tone of muscle. Genetic ablation of the orexin containing neurons in transgenic mice led to a phenotype similar to human narcolepsy. These mice models were found to be obese with hypophagia and ate less compared to their counterparts. This has led to a notion that orexinergic neurons could be involved in regulating energy metabolism along with regulation of feeding. ${ }^{12}$

Apart from regulation of sleep wake cycle and appetite, studies have demonstrated the role of orexins in activating the brain reward systems. It was found that the vesicles of the presynaptic nerve terminals containing orexin neuropeptides housed co-transmitter dynorphin. ${ }^{13}$ Dynorphin decreases reward sensitivity and is associated with depression-like state. Later, it was discovered that orexin signaling through $\mathrm{OX}_{1}$ receptors facilitate reward by antagonizing the anti-reward effects of its cotransmitter dynorphin. ${ }^{14}$ A recent study done by Flores et al revealed the role of orexin receptors in extinction of fear memories. ${ }^{15}$ This invokes further studies using orexin receptor antagonists as therapeutic targets for treatment of diseases associated with overwhelming and unreasonable fear like phobia and post-traumatic stress disorders. Although, initially thought to be orexigenic peptides, later 
orexins were found to be involved in a variety of physiological functions. It is likely that many more functions of orexin peptides are yet to be uncovered.

\section{Orexin receptors and narcolepsy}

Narcolepsy is a lifelong debilitating disorder of sleep in which the patient presents with excessive day time somnolescence, cataplexy, sleep paralysis, hypnagogic and hypnopompic hallucinations. The pathophysiology of narcolepsy remained an unsolved mystery until the discovery of orexin signaling system. The landmark discovery of orexin neuropeptides residing in the hypothalamus was followed by studies to find out the physiological role and functioning of this novel signaling molecule.

Thus, Chemelli et al created orexin gene knockout mice which lacked the precursor prepro-orexin needed for the production of orexin neuropeptides. ${ }^{16}$ The orexin deficient mice demonstrated a phenotype strikingly similar to human narcolepsy. This led to unraveling of the underlying neurobiology of narcolepsy and also opened a new dimension for physiological role played by the orexin neuropeptides in regulation of sleep/wake cycle.

Further studies were done in transgenic mice whose orexin containing neurons were genetically ablated. ${ }^{12}$ These mice also showed a phenotype similar to human narcolepsy. They showed premature entry into REM (rapid eye movement) sleep and alteration in sleep architecture. In a recent study done in orexin receptor knockout mice, it was found that replacement of orexin receptors in the dorsal raphe nucleus and locus coeruleus inhibited cataplexy like episodes and excessive sleepiness respectively. Thus, the role of serotonergic neurons of dorsal raphe nuclei and noradrenergic neurons of locus coeruleus in regulating orexin neuron dependant sleep/ wakefulness came to limelight. ${ }^{17}$

All of these data clearly indicate that any defect in orexinergic neurotransmission leads to narcolepsy. The defect could be due to either of the reasons, namely absence or deficiency of prepro-orexin neuropeptides, destruction of orexin producing neurons of hypothalamus or deficiency of orexin receptors.

One school of thought for pathophysiology of narcolepsy is due to autoimmune destruction of orexin producing neurons of the hypothalamus. ${ }^{18}$ The role of deficient orexin signaling in pathophysiology of narcolepsy was further corroborated by the findings of Nishino et al. ${ }^{19}$ They found that the CSF (cerebrospinal fluid) of majority of narcolepsy patients had undetectable levels of orexinA, unlike the controls who had normal CSF orexin-A levels. This study further added to the evidence supporting the hypo-functioning of orexinergic neurons linked to human narcolepsy phenotype.

\section{Drugs modulating orexin receptors}

\section{Orexin receptor agonists}

Orexin receptor agonists bind to and activate the $\mathrm{OX}_{1}$ and/or $\mathrm{OX}_{2}$ orexin receptors. Since $\mathrm{OX}_{1}$ and $\mathrm{OX}_{2}$ orexin receptors are involved in sleep-wake regulation, feeding, energy metabolism and reward, they are considered as potential drug targets for treatment of various disorders like narcolepsy, cataplexy, hypophagia, obesity and substance abuse. ${ }^{20}$ Though development of orexin receptor agonists has been a challenging endeavour, in 2015, Nagahara et al discovered the first selective $\mathrm{OX}_{2}$ orexin receptor agonist, compound $26 .^{21}$

It is thus possible that orexin receptor agonist may herald the future of narcolepsy treatment. Nevertheless, further studies are needed to explore their potentials as candidates for drug development.

\section{Orexin receptor antagonists}

Orexin receptor antagonists are being developed for the treatment of insomnia. Based on the selectivity of the receptors on which the drugs act, they are classified as single orexin receptor antagonist (SORA) and dual orexin receptor antagonist (DORA). ${ }^{22}$

Table 1: Single orexin receptor antagonists (SORAs). ${ }^{22}$

\begin{tabular}{|ll|}
\hline Receptor target & Pharmacological agent \\
\hline \multirow{3}{*}{ OX $_{1}$ receptor } & SB-334867 \\
\cline { 2 - 2 } & SB-408124 \\
\cline { 2 - 2 } & SB-674042 \\
\hline \multirow{3}{*}{ OX $_{\mathbf{2}}$ receptor } & TCS-335827 \\
\hline & EMPA \\
\hline
\end{tabular}

Table 2: Drug development stage of dual orexin receptor antagonists (DORAs). ${ }^{22-24}$

\begin{tabular}{|ll|}
\hline $\begin{array}{l}\text { Dual orexin } \\
\text { receptor } \\
\text { antagonist }\end{array}$ & $\begin{array}{l}\text { Phase of drug development for } \\
\text { treatment of insomnia }\end{array}$ \\
\hline $\begin{array}{l}\text { Almorexant } \\
\text { (ACT 078573) }\end{array}$ & $\begin{array}{l}\text { Completed phase III clinical trial } \\
\text { (no longer in drug development) }\end{array}$ \\
\hline DORA-22 & Preclinical development \\
\hline $\begin{array}{l}\text { Filorexant } \\
\text { (MK-6096) }\end{array}$ & $\begin{array}{l}\text { Completed phase II clinical trial } \\
\text { (no longer in drug development) }\end{array}$ \\
\hline $\begin{array}{l}\text { Lemborexant } \\
\text { (E-2006) }\end{array}$ & Completed phase II clinical trial \\
\hline $\begin{array}{l}\text { Suvorexant } \\
\text { (MK-4305) }\end{array}$ & $\begin{array}{l}\text { Completed phase IV clinical trial } \\
\text { (approved by Food and Drug } \\
\text { Administration on 14 }\end{array}$ \\
\hline
\end{tabular}


Single orexin receptor antagonists are drugs that selectively block either $\mathrm{OX}_{1}$ or $\mathrm{OX}_{2}$ orexin receptors. The first selective $\mathrm{OX}_{1}$ orexin receptor antagonist to be designed was SB-334867. It was 50 times more selective for $\mathrm{OX}_{1}$ than $\mathrm{OX}_{2}$ receptors. Unfortunately, this drug did not show promising results in animal studies. Neither it decreased the sleep latency, nor increased the duration of sleep. Thus, the drug was abandoned for treatment of insomnia. Other SORAs in the pipeline for treatment of insomnia are SB-408124, SB-674042 and ACT-335827. However, preclinical studies using these $\mathrm{OX}_{1}$ orexin receptor antagonists did not promote sleep. ${ }^{22}$ TCS-OX-229 was the first non-peptide antagonist selective for $\mathrm{OX}_{2}$ receptors. It is 250 times more selective for $\mathrm{OX}_{2}$ receptors. Other selective $\mathrm{OX}_{2}$ receptor antagonists are EMPA and JNJ-10397049. EMPA has 900 times more affinity for $\mathrm{OX}_{2}$ receptors compared to $\mathrm{OX}_{1}$ receptors. These drugs are also in preclinical phase of drug development. Although animal studies support the notion that they are sleep promoting agents, further studies on humans should be conducted in order to determine their therapeutic potentials. ${ }^{22}$ At present the selective orexin receptor antagonists are being used as biological tools to further elucidate the underlying pharmacology of orexinergic system.

Dual orexin receptor antagonists are drugs which produce a pharmacological blockade of both $\mathrm{OX}_{1}$ and $\mathrm{OX}_{2}$ orexin receptors. They elicited more pronounced sleep promoting effects compared to the single orexin receptor antagonists. This ushered a new era for insomnia management using dual orexin receptor antagonists. Various DORAs are in preclinical and clinical phase of drug development for the treatment of insomnia. Almorexant, filorexant, lemborexant and suvorexant are the DORAs which have entered into the different phases of clinical trials. Almorexant and filorexant are no longer in drug development pipeline, possibly due to safety concerns. Suvorexant is the first DORA to be approved by the US-FDA for treatment of insomnia in 2014. Thus, it took nearly 16 years since the discovery of orexinergic system for the development of a fruitful drug for pharmacotherapy of insomnia.

Almorexant was the first dual orexin receptor antagonist to enter into clinical trials. It was developed by the Swiss pharmaceutical company Actelion for treatment of insomnia. This drug has completed phase III trial RESTORA I (restore normal physiological Sleep with the orexin receptor antagonist almorexant) in 2009. In patients with insomnia, almorexant increased the total sleep time and reduced sleep latency at doses of $200 \mathrm{mg}$, given orally. However in 2011, Actelion announced that it was halting the drug's development because of an undisclosed possible safety issue and this drug is no longer in development. ${ }^{22}$

Filorexant (MK-6096) is a piperidine carboxamide dual orexin receptor antagonist developed by Merck. It has completed phase II clinical trials by March 2014. But the drug no longer appears in the Mercks development pipeline. $^{23}$

DORA-22 is an analog of MK-6096 (filorexant) which blocks both $\mathrm{OX}_{1}$ and $\mathrm{OX}_{2}$ orexin receptors. The drug is in preclinical phase of drug development. It is being evaluated in rats and dogs to explore its potential for pharmacotherapy of insomnia. ${ }^{23}$

Lemborexant (E-2006) is developed for treatment of insomnia by Eisai pharmaceuticals. It has completed phase II clinical trials by December 2014. It has shown to reduce latency of sleep onset and increase duration of sleep in insomnia patients. ${ }^{22}$

Suvorexant (MK-4305) is the first dual orexin receptor antagonist (DORA) to be approved by US-FDA (United States Food and Drug Administration) for treatment of insomnia in adults 18 years of age and older. It was developed by Merck and Co. and was approved on $13^{\text {th }}$ August 2014 for improving sleep latency and sleep maintenance in insomnia patients. Onset of sleep occurred between 56 and 68 minutes following oral ingestion of suvorexant. Time taken to reach peak suvorexant concentrations in blood is 120 minutes. $^{24}$ However, ingestion of food delays time to attain maximum drug concentration. Thus, the drug should not be taken with food if a faster sleep onset is desired. Its average half-life is 12.2 hours. Suvorexant is metabolized by cytochrome P450 (CYP) 3A4 to hydroxyl suvorexant which is inactive. It is excreted primarily through feces (66\%). It does not require any dose adjustments in patients with renal or hepatic impairment. ${ }^{24}$

In comparison to the present day pharmacotherapy for treatment of insomnia, this drug has a novel mechanism of action. Benzodiazepines and non-benzodiazepine drugs like zolpidem, zaleplon, zopiclone are the first line drugs for insomnia management and they act by modulating the GABA-A chloride ion channel. On the other hand, suvorexant inhibits the binding of orexin neuropeptides to the orexin receptors and thus suppresses wakefulness and promotes sleep.

Suvorexant was studied for doses of 10 to $80 \mathrm{mg}$ in clinical trials. However, higher doses were associated with increased incidence of adverse effects like somnolence, sleep paralysis, mild cataplexy and suicidal ideation. Thus, suvorexant was approved only for the following doses; $5 \mathrm{mg}, 10 \mathrm{mg}, 15 \mathrm{mg}$ and $20 \mathrm{mg}$ by the US FDA. The starting dose of suvorexant is $10 \mathrm{mg} /$ day, usually given 30 minutes before sleep. If $10 \mathrm{mg} /$ day of suvorexant is well tolerated but ineffective, then the dose can be increased to $20 \mathrm{mg} /$ day. It is to be noted that, suvorexant should be given only if sleep of at least 7 hours is expected. ${ }^{25}$

Suvorexant was evaluated for insomnia in three phase III trials. The trials enrolled patients aged $\geq 18$ years with insomnia. Two of the trials were conducted for duration 
of 3 months and the third trial was conducted for a period of one year. The trials had placebo as the comparator arm. Efficacy was measured subjectively (patient diaries) by subjective time to sleep onset (sTSO), subjective total sleep time (sTST), subjective wake after sleep onset (sWASO), subjective number of awakenings (sNAW), subjective quality of sleep (sQUAL), subjective refreshed feeling on waking (sFRESH); and objectively (using polysomnography) by latency to onset of persistent sleep (LPS) and wake after sleep onset (WASO). These trials demonstrated that suvorexant was superior to placebo in decreasing the sleep latency and increasing total sleep time in patients with insomnia. ${ }^{25}$ Also, a meta-analysis of the randomized placebo controlled trials of suvorexant, showed that suvorexant is effective and well tolerated in treatment of insomnia patients with difficulties in sleep onset and/or sleep maintenance. ${ }^{26}$

The primary adverse effect seen with suvorexant in clinical trials was somnolence. Major safety concerns were daytime impairment (impaired driving), additive central nervous system (CNS) depression when given with other CNS depressants, suicidal ideation, transient sleep paralysis, hallucinations and cataplexy-like symptoms. Since these adverse effects are dose dependant, only lower doses of suvorexant were approved by FDA. Other adverse effects observed were diarrhoea, xerostomia, upper respiratory tract infections, headache, dizziness and abnormal dreams. So far, clinical trials with orexin antagonists have not shown to produce narcolepsy. Suvorexant is contraindicated for use in patients with narcolepsy. ${ }^{26}$

\section{Advantages of suvorexant over older hypnotics}

Suvorexant induces more physiological sleep compared to benzodiazepines. Dual orexin receptor antagonists enhance rapid eye movement (REM) sleep unlike benzodiazepines which suppresses REM sleep. ${ }^{22}$ Also compared to other sleeping pills, suvorexant has better adverse effect profile. It has reduced incidence of drowsiness, cognitive dysfunction and does not produce amnesia, rebound insomnia as well as drug dependence. Based on its abuse potential, it is included under schedule IV of controlled substances by United States drug enforcement administration.

Following the FDA approval of suvorexant, it is speculated that more orexin receptor antagonists might hit the market in near future. But whether these newer groups of drugs modulating the orexinergic system uproot the older hypnotics with regard to their better safety profile still remains unanswered. Being a new drug, its long term safety is not yet established. However, they have become important targets in drug development research.

\section{CONCLUSION}

Orexins are neuropeptides produced from the lateral hypothalamus. They are involved in a wide range of physiological functions like regulation of sleep-wake cycle, feeding, energy metabolism and reward. The therapeutic potential of modulating the orexin signaling for pharmacotherapy of various diseases was undertaken by various researchers since the time of their discovery. Orexin receptor agonists have potential to be used for pharmacotherapy of narcolepsy, cataplexy, hypophagia, obesity and substance abuse. However, no orexin receptor agonist has entered clinical phase of drug development. Orexin receptor antagonists have become important targets in drug development research for insomnia. Suvorexant is the first orexin receptor antagonist to be approved for treatment of insomnia. However it is possible that the orexinergic system would provide many more drug targets for various diseases in the near future.

Funding: No funding sources

Conflict of interest: None declared

Ethical approval: Not required

\section{REFERENCES}

1. De LL, Kilduff TS, Peyron C, Gao XB, Foye PE, Danielson PE, et al. The hypocretins: hypothalamusspecific peptides with neuroexcitatory activity. Proc Natl Acad Sci. 1998;95:322-7.

2. Sakurai T, Amemiya A, Ishii M, Matsuzaki I, Chemelli RM, Tanaka H, et al. Orexins and orexin receptors: a family of hypothalamic neuropeptides and $G$ protein-coupled receptors that regulate feeding behavior. Cell. 1998;92:573-85.

3. Gotter AL, Webber AL, Coleman PJ, Renger JJ, Winrow CJ. International union of basic and clinical pharmacology. orexin receptor function, nomenclature and pharmacology. Pharmacol Rev.2012;64:389-420.

4. Kukkonen JP, Holmqvist T, Ammoun S, Akerman KEO. Functions of the orexinergic/hypocretinergic system. AJP Cell Physiol. 2002;283:567-91.

5. De LL, Huerta R. Hypocretin (orexin) regulation of sleep-to-wake transitions. Front Pharmacol. 2014;5:16.

6. Karteris E, Machado RJ, Chen J, Zervou S, Willhouse EW, Randeva HS. Food deprivation differentially modulates orexin receptor expression and signaling in rat hypothalamus and adrenal cortex. AJP Endocrinol Metab. 2005;288:1089-100.

7. Holmqvist T, Johansson L, Ostman M, Ammoun S, Akerman KEO, Kukkonen JP. OX ${ }_{1}$ orexin receptors couple to adenylyl cyclase regulation via multiple mechanisms. J Biol Chem. 2005;280:6570-9.

8. Urbańska A, Sokołowska P, Woldan TA, Biegańska $\mathrm{K}$, Brix B, Jöhren $\mathrm{O}$, et al. orexins/hypocretins acting at gi protein-coupled $\mathrm{OX}_{2}$ receptors inhibit cyclic amp synthesis in the primary neuronal cultures. J Mol Neurosci. 2012;46:10-7. 
9. Jantti M, Putula J, Somerharju P, Frohman M, Kukkonen J. $\mathrm{OX}_{1}$ orexin/hypocretin receptor activation of phospholipase D: $\mathrm{OX}_{1}$ activates PLD. Br J Pharmacol. 2012;165:1109-23.

10. Leonard CS, Kukkonen JP. Orexin/hypocretin receptor signalling: a functional perspective. $\mathrm{Br} \mathrm{J}$ Pharmacol. 2014;171:294-313.

11. Lee MG. Discharge of identified orexin/hypocretin neurons across the sleep-waking cycle. J Neurosci. 2005;25:6716-20.

12. Hara J, Beuckmann CT, Nambu T, Willie JT, Chemelli RM, Sinton CM, et al. Genetic ablation of orexin neurons in mice results in narcolepsy, hypophagia, and obesity. Neuron. 2001;30:345-54.

13. Chou TC, Lee CE, Lu J, Elmquist JK, Hara J, Willie JT, et al. Orexin (hypocretin) neurons contain dynorphin. J Neurosci. 2001;21:1-6.

14. Muschamp JW, Hollander JA, Thompson JL, Voren G, Hassinger LC, Onvani S, et al. Hypocretin (orexin) facilitates reward by attenuating the antireward effects of its cotransmitter dynorphin in ventral tegmental area. Proc Natl Acad Sci. 2014;111:1648-55.

15. Flores Á, Valls CV, Costa G, Saravia R, Maldonado $\mathrm{R}$, Berrendero F. The hypocretin/orexin system mediates the extinction of fear memories. Neuro Psychopharmacology. 2014;39:2732-41.

16. Chemelli RM, Willie JT, Sinton CM, Elmquist JK, Scammell T, Lee C, et al. Narcolepsy in orexin knockout mice: molecular genetics of sleep regulation. Cell. 1999;98:437-51.

17. Hasegawa E, Yanagisawa M, Sakurai T, Mieda M. Orexin neurons suppress narcolepsy via 2 distinct efferent pathways. J Clin Invest. 2014;124:604-16.
18. Mahlios J, De HA, Mignot E. The autoimmune basis of narcolepsy. Curr Opin Neurobiol. 2013;23:767-73.

19. Nishino S, Ripley B, Overeem S, Nevsimalova S, Lammers GJ, Vankova J, et al. Low cerebrospinal fluid hypocretin (Orexin) and altered energy homeostasis in human narcolepsy. Ann Neurol. 2001;50:381-8.

20. Heifetz A, Bodkin MJ, Biggin PC. Discovery of the first selective, nonpeptidic orexin 2 receptor agonists. J Med Chem. 2015;58:7928-30.

21. Nagahara T, Saitoh T, Kutsumura N, IrukayamaTomobe Y, Ogawa Y, Kuroda D, et al. design and synthesis of non-peptide, selective orexin receptor 2 agonists. J Med Chem. 2015;58:7931-7.

22. Equihua AC, De HA, Drucker CR. Orexin receptor antagonists as therapeutic agents for insomnia. Front Pharmacol. 2013;4:163.

23. Winrow CJ, Renger JJ. Discovery and development of orexin receptor antagonists as therapeutics for insomnia. Br J Pharmacol. 2014;171:283-93.

24. Bennett T, Bray D, Neville MW. Suvorexant, a dual orexin receptor antagonist for the management of insomnia. Physical Therapy J. 2014;39:265-6.

25. Rhyne DN, Anderson SL. Suvorexant in insomnia: efficacy, safety and place in therapy. Ther Adv Drug Saf. 2015;6:189-95.

26. Kishi T, Matsunaga S, Iwata N. Suvorexant for primary insomnia: a systematic review and metaanalysis of randomized placebo-controlled trials. Plos One. 2015;10:0136910.

Cite this article as: Nishanthi $\mathrm{A}$, Vimal M, Sandhiya S, Dkhar SA. Orexin receptors: a journey through their discovery to the development of suvorexant, the new sleeping pill. Int J Basic Clin Pharmacol 2016;5:573-8. 